\title{
Spatial distribution of Glossina sp. and Trypanosoma sp. in south-western Ethiopia
}

Reta Duguma ${ }^{1,2}$, Senbeta Tasew ${ }^{3}$, Abebe Olani ${ }^{4}$, Delesa Damena ${ }^{4}$, Dereje Alemu ${ }^{3}$, Tesfaye Mulatu ${ }^{4}$, Yoseph Alemayehu ${ }^{5}$, Moti Yohannes ${ }^{6}$, Merga Bekana ${ }^{1}$, Antje Hoppenheit ${ }^{7}$, Emmanuel Abatih $^{8}$, Tibebu Habtewold ${ }^{2}$, Vincent Delespaux ${ }^{8^{*}}$ (i) and Luc Duchateau ${ }^{2}$

\begin{abstract}
Background: Accurate information on the distribution of the tsetse fly is of paramount importance to better control animal trypanosomosis. Entomological and parasitological surveys were conducted in the tsetse belt of south-western Ethiopia to describe the prevalence of trypanosomosis (PoT), the abundance of tsetse flies (AT) and to evaluate the association with potential risk factors.

Methods: The study was conducted between 2009 and 2012. The parasitological survey data were analysed by a random effects logistic regression model, whereas the entomological survey data were analysed by a Poisson regression model. The percentage of animals with trypanosomosis was regressed on the tsetse fly count using a random effects logistic regression model.

Results: The following six risk factors were evaluated for PoT (i) altitude: significant and inverse correlation with trypanosomosis, (ii) annual variation of PoT: no significant difference between years, (iii) regional state: compared to Benishangul-Gumuz (18.0\%), the three remaining regional states showed significantly lower PoT, (iv) river system: the PoT differed significantly between the river systems, (iv) sex: male animals (11.0 \%) were more affected than females (9.0\%), and finally (vi) age at sampling: no difference between the considered classes. Observed trypanosome species were T. congolense (76.0 \%), T. vivax (18.1\%), T. b. brucei (3.6\%), and mixed T. congolense/vivax (2.4\%).

The first four risk factors listed above were also evaluated for AT, and all have a significant effect on AT. In the multivariable model only altitude was retained with AT decreasing with increasing altitude. Four different Glossina species were identified i.e. G. tachinoides (52.0 \%), G. pallidipes (26.0\%), G.morsitans submorsitans (15.0\%) and G. fuscipes fuscipes (7.0\%). Significant differences in catches/trap/day between districts were observed for each species. No association could be found between the tsetse fly counts and trypanosomosis prevalence.

Conclusions: Trypanosomosis remains a constraint to livestock production in south-western Ethiopia. Four Glossina and three Trypanosoma species were observed. Altitude had a significant impact on AT and PoT. POT is not associated with AT, which could be explained by the importance of mechanical transmission. This needs to be investigated further as it might jeopardize control strategies that target the tsetse fly population.
\end{abstract}

Keywords: Trypanosoma, Glossina, Ethiopia, Cattle, Risk factors

\footnotetext{
* Correspondence: vdelespaux@itg.be

${ }^{8}$ Department of Biomedical Sciences, Institute of Tropical Medicine,

Nationalestraat 155, Antwerp, Belgium

Full list of author information is available at the end of the article
} 


\section{Background}

In sub-Saharan Africa, trypanosomosis is responsible for poverty, weak economic growth and low agricultural production resulting in subsistence livelihood [1-4]. In regions under challenge of trypanosomosis, land cannot be exploited for livestock rearing. The resulting lack of draught power is further compromising crop production. In rural Africa, livestock breeding constitutes an alternative banking system and contributes to social wealth and welfare. However, 48 million $(=30.0 \%)$ African cattle, not including other livestock species, are exposed to trypanosomosis [5].

Ethiopia covers an area of 1.1 million $\mathrm{km}^{2}$ with $240,000 \mathrm{~km}^{2}$ of fertile areas under threat of trypanosomosis. Particularly affected are the western and southern lowlands, preventing agricultural activities. Drastic droughts in the 70's and early 80's have caused a significant number of people to move from the northern highlands to the tsetse-infested south-western region in search of fertile land [6]. Since the 70's, this situation has worsened by repeated abnormal climatic fluctuations linked to El Niño [7]. Furthermore, new governmental land use regulations that were adopted between 1987 and 2005 resulted in a threefold increase in utilised agricultural land $[8,9]$. This "demographic" clearing, whose effects are comparable to the bush clearing strategy of colonial Africa, substantially changed the distribution and abundance of the different tsetse species, deemed to be the most important vector for trypanosomes [10]. Currently, 14.8 million cattle, 6.1 million sheep and goats, and 1.2 million equines are at risk of trypanosomosis in this recently settled south-western region. Tsetse control is organised by the Ethiopian government through NICETT (National Institute for the Control and Eradication of Tsetse and Trypanosomosis); formerly represented by STEP (Southern Tsetse Eradication Program). Their strategies comprise the use of insecticidal pour-ons and insecticide impregnated traps and targets. Complementary to those vector control activities, trypanocidal drug treatment remains the most widely used control strategy because it is available and most affordable for livestock breeders. Trypanocides minimize the impact of the parasite on animal health and also reduce the period that the animal is infectious for possible vectors [11]. The presence of single and multiple drug resistant trypanosome strains in different locations [12-14] is hampering the success of chemotherapeutic and prophylactic approaches. For decades, the association of vector control and chemotherapy has been used to minimize the risk and impact of trypanosomosis [15]. However, despite more than 30 years of various attempts of tsetse and trypanosomosis control, tsetse flies have expanded their distribution and reinvaded previously tsetse-free areas at a rate of $200 \mathrm{~m} /$ year [16, 17]. This failure in achieving sustainable results is explained through fragmented and uncoordinated actions induced by poor information coupled with the absence of longterm coherent policies [18]. Tsetse populations are highly resilient; populations seem to restore and expand as soon as control measures are discontinued [19]. Accurate data on vector and parasite distributions as well as on risk factors for trypanosomosis among the domestic hosts are of paramount importance to control the disease with the ultimate goal of achieving eradication.

Despite the importance of such data, the last countrywide census on tsetse flies and trypanosomosis was conducted by Langridge in 1976 [20]. The aim of this study was thus (i) to update the available data by conducting large entomological and parasitological surveys and (ii) to identify the main risk factors influencing the transmission of the disease.

\section{Methods}

\section{Study region}

The study was conducted in south-western Ethiopia. The parasitological survey was conducted in a region located between $7^{\circ} 12^{\prime}$ to $10^{\circ} 09^{\prime} \mathrm{N}$ latitude and $34^{\circ} 39^{\prime}$ to $35^{\circ} 00^{\prime} \mathrm{E}$ longitude and the entomological survey between $8^{\circ} 22^{\prime}$ to $12^{\circ} 13^{\prime} \mathrm{N}$ latitude and $35^{\circ} 32^{\prime}$ to $37^{\circ} 28^{\prime} \mathrm{E}$ longitude (Figs. 1 and 2). The altitudes of the study regions ranged between 1040 and $2012 \mathrm{~m}$ and between 628 and 1673 m.a.s.l. (metres above sea level) for the parasitological and the entomological surveys, respectively. The region contains a hydrographic network including the Abay (Blue Nile), Didessa, Anger, Baro Akobo, Birbir, Dabus, Ghibe and Tekeze rivers and their tributaries. The Abay Didessa has a runoff of 52.6 billion $\mathrm{m}^{3} /$ year and covers $199,812 \mathrm{~km}^{2}$ catchment area with elevation ranging from 500 to $4261 \mathrm{~m}$. The Boro-Akobo has 23.6 billion $\mathrm{m}^{3}$ /year runoff and covers $75,912 \mathrm{~km}^{2}$ catchment area with elevation ranging from 390 to $3244 \mathrm{~m}$. The Ghibe-Omo river has 17.9 billion m3/year runoff, $79,000 \mathrm{~km} 2$ catchment area and a variety of wildlife parks [21]. There are two rainy seasons: the short one from the end of February to the end of April and the long one from June to September. The current study area includes four of the ten ecosystems of the country i.e. (i) woodland, (ii) lowland tropical forest, (iii) montane moist forest and (iv) montane dry evergreen [22]. The primary forests in these ecosystems together with the river networks constitute sanctuaries for tsetse flies and diverse wildlife [23] despite an intense deforestation rate. Firewood and land to feed the growing population are the main causes of encroachment [24]. Livestock is mainly fed on crop residues (at the end of the rainy season, beginning of the dry season) and on naturally persistent pastures. As most of the land is intensively cultivated during the long rainy season, cattle are moved to the vicinity of the forests where permanent grassland is 


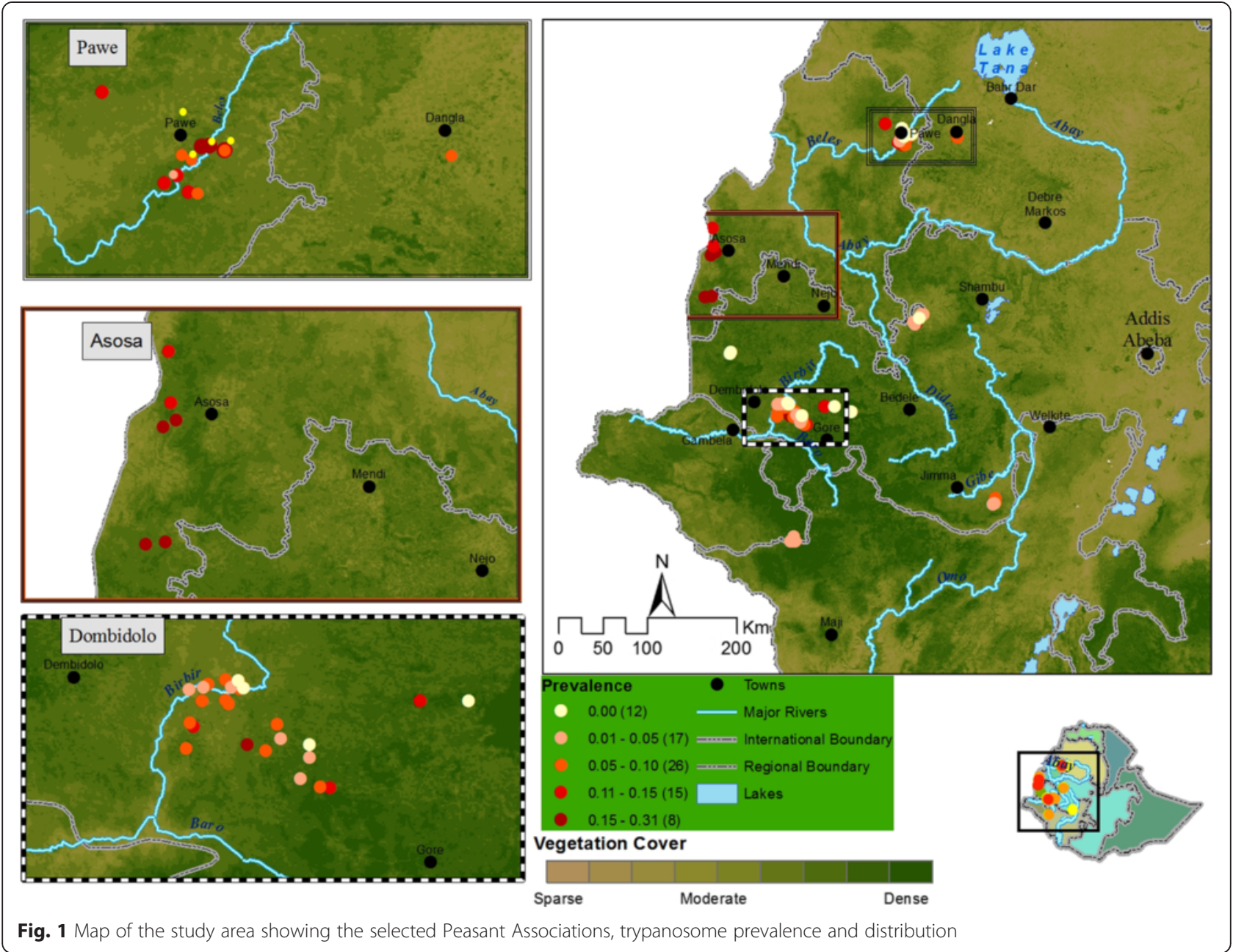

available to avoid damage to the crops. Cattle are the dominant livestock species. The Horro breed is concentrated in the southwest and west of Ethiopia, the Abigar (Nuer) breed in the Gambela region, the Gurage breed in the Gurage zone and the Fogera breed in northwest Ethiopia in Amhara region [25].

Trypanosomosis occurs in five of the nine Ethiopian regional states (Oromia, Amhara, Gambela, BenishangulGumuz and Southern Nations Nationalities and Peoples Region) comprising 240,000 $\mathrm{km}^{2}$ of land area. Sampling was only carried out in 4 states (excluding Southern Nations Nationalities and Peoples Region). From the 4 regional states, eleven districts were purposively selected based on the burden of trypanosomosis reported by farmers and based on the expert opinion of local veterinarians. Local experts used financial cost, morbidity, mortality and withdrawal from draft power as criteria to estimate the trypanosomosis burden. The 11 districts comprise a total of 340 peasant associations (PA). A PA is the lowest administrative structure in Ethiopia with an average land area of $53 \mathrm{~km}^{2}$. The tributaries in the vicinity of each PA (within a
$3.5 \mathrm{~km}$ radius) were allocated to one of the four main river systems, i.e., Ghibe, Baro-Akobo, Abay (Blue Nile) and Abay-Didessa.

\section{Sampling frame}

Two-hundred PAs served as sampling frame since 140 had to be excluded from the study due to poor accessibility.

A total of 30 PAs (Fig. 1) were selected at random from the accessible 200 PAs, and both a parasitological and entomological survey was carried out in those 30 PAs. In another set of 52 randomly selected PAs, only a parasitological survey was done, and in another set of eight randomly selected PAs, only an entomological survey was carried out. Therefore, an entomological survey was conducted in 38 PAs in seven of the above selected 11 districts. Additionally, only an entomological survey was done in 14 PAs that were randomly selected from 92 PAs in 3 districts (which were not a subset of the above 11 districts); thus entomological surveys were done in a total of 52 PAs in 10 districts in this study. These 3 districts (Quara, Chora Botor and Darimu) were purposively included. 

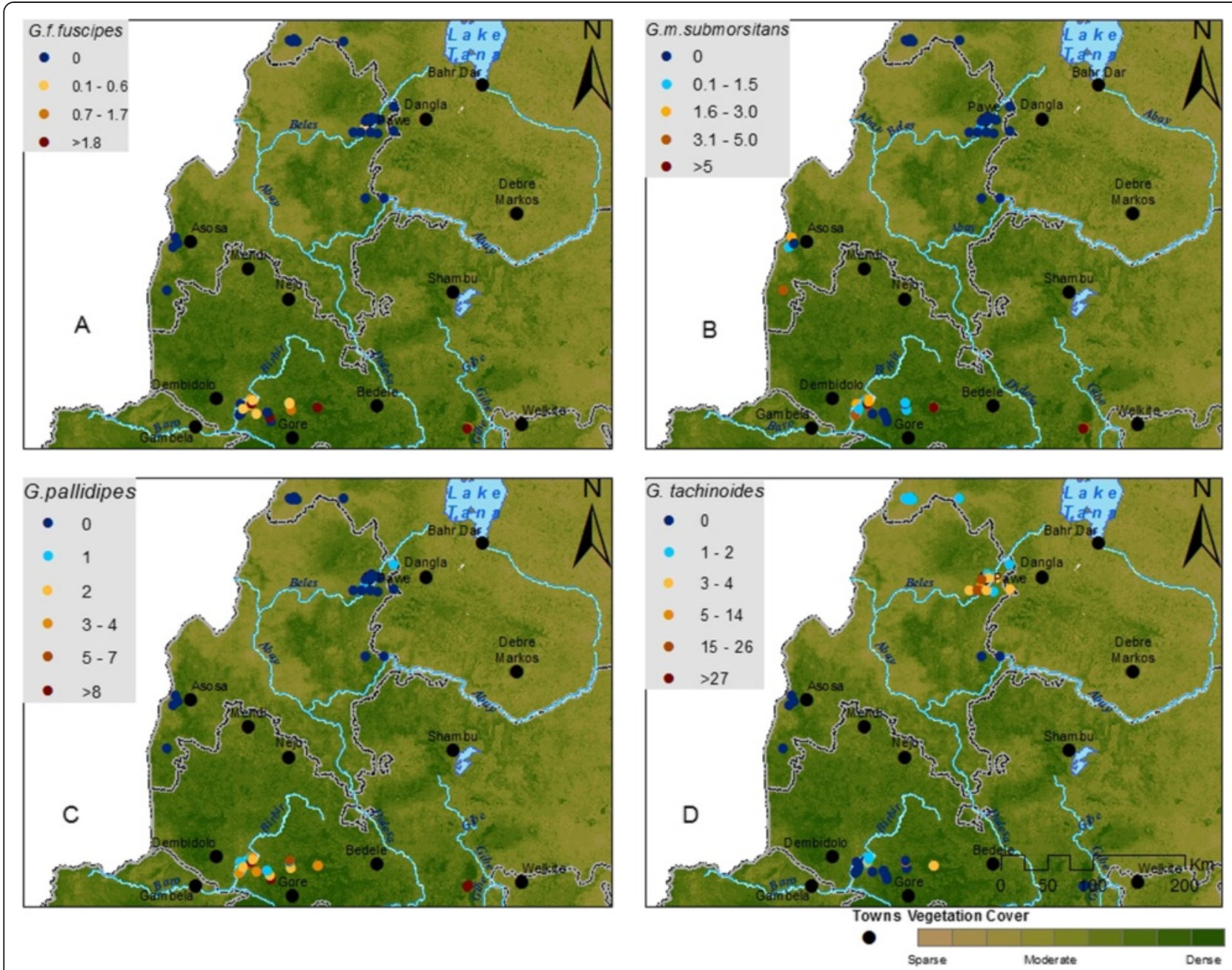

Fig. 2 Map showing the selected Peasant Associations: tsetse fly catches and distribution

Quara district in north Amhara region, Chora Botor district in Oromia bordering Ghibe valley and Shewa highlands and Darimu district in Oromia bordering Birbir valley and Ilu-Abaabora highlands that have been reported to be the limit of tsetse fly distribution as per the information from Zonal Veterinary offices.

Within each PA selected for parasitological survey, a minimum of 75 heads of cattle were selected at random and sampled, which led to a total of 7021 animals from those 82 PAs in 11 districts (on average 85 heads of cattle/PA).

\section{Parasitological survey}

Between 2009 and 2012, blood samples were collected from these 7021 animals. The geographical reference of the PA, the number of animals sampled per PA and their age (based on teeth method), sex and trypanosome infection status were recorded. Sampling took place during the 5 months of the dry season (October to February) and the 3 months of the short rainy season (March to May), but each PA was only sampled once. Blood was taken from the ear vein, collected in a heparinized capillary tube and centrifuged by the Micro-Haematocrit Centrifugation Technique [26]. A minimum of 50 fields were examined using a standard light microscopy at 400x magnification. Trypanosomes were identified according to their movement pattern and later confirmed by the examination of Giemsa stained thin smears [27].

The experimental protocol and sampling were approved by the Ethical Committee of Addis Ababa University and the Zonal Agricultural Bureau. The background of the study was explained to the Peasant Associations and consent of the farmers was asked for sampling of their animals.

\section{Entomological survey}

For the entomological survey, a total of 1046 monopyramidal traps [28] were deployed in the 52 PAs. Three tsetse fly attractants (acetone, octenol and cow urine) were used [29, 30]. Traps were deployed for 2 days and 
flies were collected twice a day at around 10:00 AM and 6:00 PM. Tsetse flies were counted, species and sex were determined. The number of tsetse flies captured per trap per day was used as indicator of the AT.

\section{Data analysis}

The relationship between the presence of trypanosomes and the potential risk factors of altitude, sampling year, regional state, river system, sex and age was modelled by a random effects logistic regression model with PA incorporated as random effect [31]. First, each potential risk factor was included alone in the model (univariate analysis), next, potential risk factors with a p-value lower than 0.10 in the univariate analysis were incorporated jointly [32], together with their two-way interactions (multivariate analysis), and the forward selection procedure was applied to obtain the final model [33]. The odds ratio with its $95 \%$ confidence interval was used as summary statistic.

The AT of tsetse flies in each PA was given by the number of flies captured in all deployed traps. The relationship between the AT in a PA and the potential risk factors of altitude, sampling year, regional state and river system was modelled by a Poisson regression model with the number of traps in the PA included as fixed offset term [34]. First, each potential risk factor was included alone in the model (univariate analysis), next potential risk factors with a pvalue lower than 0.10 in the univariate analysis were incorporated jointly, together with their two-way interactions (multivariate analysis), and the forward selection procedure was applied to obtain the final model. The incidence rate ratio (IRR) with its $95 \%$ confidence interval was used as summary statistic.

The distribution of the ATs over the four different species was compared between the districts using the Kruskall-Wallis test. The difference of the total number of tsetse flies of the two sexes within each trap was compared for each Glossina species separately using the Wilcoxon rank sum test stratified for trap.

Finally, the relationship between trypanosome presence and $\mathrm{AD}$ was investigated by a random effect logistic regression model with PA incorporated as random effect, the trypanosome status of the animal as response variable and the $\mathrm{AD}$ in the PA as risk factor.

\section{Results}

Trypanosomosis prevalence, distribution and risk factors Out of 7021 examined cattle, 675 (9.61 \%) were trypanosome-positive. The predominant species was $T$. congolense (76.0 \%), followed by T. vivax (18.1\%), T. $b$. brucei (3.6\%), and mixed T. congolense/vivax infections (2.4\%). Trypanosomosis prevalence varied significantly between the PAs. In $14.6 \%$ of the PAs $(n=12)$, no trypanosomes were detected. The results are summarized in
Fig. 1. When compared to Benishangul-Gumuz (18.0\%), the 3 other regional states had a significantly lower trypanosomosis burden: Amhara (12.0\%), Oromia (6.0\%) and Gambela (5.0\%).

In the univariate model (Table 1), low altitude was significantly and inversely associated with trypanosomosis. Geographical regions with an altitude lower or equal to $1200 \mathrm{~m}$ showed the highest trypanosomosis prevalence (12.0\%). Annual variation of the trypanosomosis burden was not significant between years. The highest and lowest trypanosomosis prevalence was observed at the first year $(11.0 \%)$ and the last year $(4.0 \%)$, respectively. Male animals $(11.0 \%)$ were significantly more often affected than females $(9 \%, p=0.01)$. The distribution of trypanosomosis also varied significantly between the different river systems: the prevalence was correlated with the size of the river system with $5.0 \%$ around the Ghibe river (17.9 billion $\mathrm{m}^{3}$ /year), $7.0 \%$ around the Boro-Akobo (23.6 billion $\mathrm{m}^{3} /$ year), $11.0 \%$ around the Abay/Blue Nile and $15.0 \%$ around the enlarged Abay Didessa (52.6 billion $\mathrm{m}^{3} /$ year) [21]. The different age classes did not differ significantly with respect to trypanosomosis burden. The highest and lowest trypanosomosis prevalence was observed in cattle of age $>4$ years $(11.0 \%)$ and $\leq 2$ years $(6 \%)$, respectively. In the final multivariable model, only altitude and sex had a significant effect (Table 2) confirming the trend of the univariate analysis.

\section{Distribution, abundance and risk factors of Tsetse flies}

A total of 14,698 tsetse flies were trapped. Four different species were identified i.e. G. tachinoides (52\%), G. pallidipes (26\%), G. morsitans submorsitans (15\%) and G. fuscipes fuscipes (7\%). Significant differences in AD between districts were observed globally and for each of the Glossina species separately $(p<0.0001)$. The mean figure for $\mathrm{AD}$ was 7.45 catches/trap/day but considerable differences between PAs were observed. No catches were recorded at four PAs, i.e. Awjeben (Qwara district), Silga 22 (Asosa district), Tsiwuli and Yimale (Guangua district) and up to 78 catches/trap/day in the Pawe district. The AD and distribution across sampled PAs is shown in Fig. 2. G. tachinoides was the sole species trapped in the PAs of Guangua, Jawi, Pawe and Qwara districts. In the PAs of Asosa district, only G. m. submorsitans was trapped whilst all four tsetse species were detected in the PAs of Dalesadi and Dalewabara. Two species were observed in the PAs of Darimu district (pallidipes and fuscipes), of Hawagelan district (pallidipes and submorsitans), whereas in Choraboter district three species (submorsitans, pallidipes and fuscipes) were observed. More female than male tsetse were trapped with $53 \%$ and $47 \%$ respectively $(p=0.01)$. This was also the case for each species considered individually (Table 3 ). 
Table 1 Distribution of cattle trypanosomosis among potential risk factors and univariate analysis

\begin{tabular}{|c|c|c|c|c|c|}
\hline Risk factor & Category & $\mathrm{N}(\mathrm{N}+)$ & Prevalence & $95 \% \mathrm{Cl}$ & $p$-value \\
\hline \multirow[t]{6}{*}{ Altitude } & $\leq 1200 \mathrm{~m}$ & $971(118)$ & $12.2 \%$ & $10.2,14.4$ & \multirow[t]{6}{*}{0.0002} \\
\hline & $>1200 \mathrm{~m}, \leq 1300 \mathrm{~m}$ & $518(43)$ & $8.3 \%$ & $6.1,11.0$ & \\
\hline & $>1300 \mathrm{~m}, \leq 1400 \mathrm{~m}$ & $910(65)$ & $7.1 \%$ & $5.6,9.0$ & \\
\hline & $>1400 \mathrm{~m}, \leq 1500 \mathrm{~m}$ & $2936(334)$ & $11.4 \%$ & $10.2,12.6$ & \\
\hline & $>1500 \mathrm{~m}, \leq 1600 \mathrm{~m}$ & $1074(86)$ & $8.0 \%$ & $6.5,9.8$ & \\
\hline & $>1600 \mathrm{~m}$ & $612(29)$ & $4.7 \%$ & $3.2,6.7$ & \\
\hline \multirow[t]{4}{*}{ Year } & 2009 & $3191(345)$ & $10.8 \%$ & $9.8,11.9$ & \multirow[t]{4}{*}{0.2154} \\
\hline & 2010 & $2619(255)$ & $9.7 \%$ & $8.6,10.9$ & \\
\hline & 2011 & $1054(68)$ & $6.5 \%$ & $5.0,8.1$ & \\
\hline & 2012 & $157(7)$ & $4.5 \%$ & $0.18,9.0$ & \\
\hline \multirow[t]{4}{*}{ Regional state } & Benshangul-Gumuz & 1763(312) & $17.7 \%$ & $15.9,19.6$ & \multirow[t]{4}{*}{0.0002} \\
\hline & Amhara & $552(65)$ & $11.8 \%$ & $9.2,14.8$ & \\
\hline & Oromia & $4214(271)$ & $6.4 \%$ & $5.7,7.2$ & \\
\hline & Gambela & $492(27)$ & $5.5 \%$ & $3.6,7.9$ & \\
\hline \multirow[t]{2}{*}{ Sex } & Male & $3356(355)$ & $10.6 \%$ & $9.6,11.7$ & \multirow[t]{2}{*}{0.0102} \\
\hline & Female & $3665(320)$ & $8.7 \%$ & $7.8,9.7$ & \\
\hline \multirow[t]{4}{*}{ River system } & Abay Didessa & $1688(256)$ & $15.2 \%$ & $13.5,17.0$ & \multirow[t]{4}{*}{0.0419} \\
\hline & Abay & $1294(145)$ & $11.2 \%$ & $9.5,13.1$ & \\
\hline & Baro Akobo & $3377(240)$ & $7.1 \%$ & $6.3,8.0$ & \\
\hline & Ghibe & $662(34)$ & $5.1 \%$ & $3.6,7.1$ & \\
\hline \multirow[t]{3}{*}{ Age (years) } & $>4$ & 4096 (435) & $10.6 \%$ & $9.7,11.6$ & \multirow[t]{3}{*}{0.2211} \\
\hline & $>2, \leq 4$ & $2321(201)$ & $87 \%$ & $7.5,9.9$ & \\
\hline & $\leq 2$ & 604 (39) & $6.5 \%$ & $4.6,8.7$ & \\
\hline
\end{tabular}

With $N$ number sampled, $(N+)$ number positive, $\mathrm{Cl}$ Confidence Interval

In the univariate model (Table 4), all risk factors had a significant effect on $\mathrm{AD}$, but only altitude was retained in the multivariable analysis. Low altitude was significantly and positively associated with AT. Geographical regions with an altitude lower or equal to $1200 \mathrm{~m}$ showed the highest average count of 17.1 catches/trap/ day. Astonishingly, geographical regions above $1500 \mathrm{~m}$ showed an unexpected high average count of 12 . This is

Table 2 The final multivariable model presenting the risk factors associated with trypanosomosis in Ethiopia

\begin{tabular}{llcll}
\hline Risk factor & Category & Odds ratio & $95 \% \mathrm{Cl}$ & $\mathrm{p}$-value \\
\hline Altitude & $\leq 1200 \mathrm{~m}^{\mathrm{a}}$ & 1 & - & - \\
& $>1200 \mathrm{~m}, \leq 1300 \mathrm{~m}$ & 0.27 & $(0.14,0.51)$ & $<0.001$ \\
& $>1300 \mathrm{~m}, \leq 1400 \mathrm{~m}$ & 0.40 & $(0.20,0.80)$ & 0.009 \\
& $>1400 \mathrm{~m}, \leq 1500 \mathrm{~m}$ & 0.53 & $(0.32,0.90)$ & 0.019 \\
& $>1500 \mathrm{~m}, \leq 1600 \mathrm{~m}$ & 0.32 & $(0.15,0.65)$ & 0.002 \\
& $>1600 \mathrm{~m}$ & 0.34 & $(0.15,0.74)$ & 0.007 \\
Sex & Female & 1 & - & - \\
& Male & 1.25 & $(1.06,1.49)$ & 0.01 \\
\hline
\end{tabular}

With $\mathrm{Cl}$ Confidence Interval, ${ }^{a}$ reference linked to one single PA (Abuna Gali) where the AT was abnormally high.

Finally, no relationship between AT and trypanosomosis prevalence was found $(\mathrm{OR}=1,95 \% \mathrm{CI}$ : [0.99;1], $p=0.348)$.

\section{Discussion}

\section{Trypanosomosis}

The overall prevalence of trypanosomosis was $9.6 \%$. Using the same parasitological technique for diagnosis, a comparable prevalence was reported in north-western Ethiopia at Jawi district [35] and the western Oromia regional state [36]. Prevalence in the PAs ranged from $1.1 \%$ to $30.8 \%$. T. congolense was the most predominant species $(76.0 \%)$ followed by $T$. vivax $(18.1 \%)$ and $T$. brucei (3.6 \%). This is in agreement with the observations made by other groups in different tsetse-infested areas in Ethiopia [12, 20, 35-37].

Altitude is a well-known limiting factor for cattle trypanosomosis. The altitudinal difference in trypanosomosis burden is most often explained by the significant variation in tsetse densities across altitudes [38], but this 
Table 3 Distribution of tsetse flies by species, sex and district

\begin{tabular}{|c|c|c|c|c|c|c|c|c|c|c|c|c|c|c|}
\hline \multirow[t]{2}{*}{ District } & \multirow[t]{2}{*}{ n.s. } & \multicolumn{3}{|c|}{ G. m. submorsitans } & \multicolumn{3}{|c|}{ G. pallidipes } & \multicolumn{3}{|c|}{ G.f. fuscipes } & \multicolumn{3}{|c|}{ G. tachinoides } & \multirow[b]{2}{*}{$\Sigma \Sigma$} \\
\hline & & M & $\mathrm{F}$ & $\Sigma$ & M & $\mathrm{F}$ & $\Sigma$ & $\mathrm{M}$ & $\mathrm{F}$ & $\Sigma$ & M & $\mathrm{F}$ & $\Sigma$ & \\
\hline Dalesadi & 4 & 230 & 456 & 686 & 337 & 700 & 1037 & 78 & 151 & 229 & 74 & 74 & 148 & 2100 \\
\hline Dalewabera & 4 & 197 & 320 & 517 & 198 & 388 & 586 & 147 & 220 & 367 & 163 & 207 & 370 & 1840 \\
\hline Choraboter & 3 & 389 & 281 & 670 & 777 & 329 & 1106 & 207 & 150 & 357 & - & - & - & 2133 \\
\hline Hawagelan & 3 & 69 & 121 & 190 & 127 & 247 & 374 & 1 & 6 & 7 & - & - & - & 571 \\
\hline Darimu & 2 & - & - & - & 185 & 483 & 668 & 49 & 62 & 111 & - & - & - & 779 \\
\hline Asosa & 1 & 41 & 93 & 134 & - & - & - & - & - & - & - & - & - & 134 \\
\hline Guangua & 1 & - & - & - & - & - & - & - & - & - & 226 & 210 & 436 & 436 \\
\hline Jawi & 1 & - & - & - & - & - & - & - & - & - & 341 & 350 & 691 & 691 \\
\hline Pawe & 1 & - & - & - & - & - & - & - & - & - & 3081 & 2762 & 5843 & 5843 \\
\hline Qwara & 1 & - & - & - & - & - & - & - & - & - & 62 & 109 & 171 & 171 \\
\hline$\Sigma$ & & 926 & 1271 & 2197 & 1624 & 2147 & 3771 & 482 & 589 & 1071 & 3947 & 3712 & 7659 & 14698 \\
\hline \multicolumn{2}{|l|}{$p$-value } & \multicolumn{3}{|c|}{$p<0.001$} & \multicolumn{3}{|c|}{$p<0.001$} & \multicolumn{3}{|c|}{$p=0.047$} & \multicolumn{3}{|c|}{$p=0.577$} & \\
\hline
\end{tabular}

With $n . s$ number of species, $M$ Male, $F$ Female, $\Sigma=$ Total, $\Sigma \Sigma=$ Grand total, $p$-values refer to comparison between sexes

point will be discussed later when describing the relationship between trypanosomosis and AT.

The annual variation in trypanosomosis prevalence was not significant from one year to another. However, the trend goes towards a decrease in prevalence, which is in line with the growing intensity of human encroachment and the resulting land use changes. It might also be explained by the intensity of control by NICETT but we do not have data to perform the analysis to substantiate it.

The highest prevalence of trypanosomosis was observed in PAs of the Asosa district where one single species of Glossina was trapped (G. morsitans submorsitans). This can be explained by the higher susceptibility of the

Table 4 Average tsetse fly counts among potential risk factors and univariate analysis

\begin{tabular}{llccc}
\hline Risk factor & Category & Average count & $95 \% \mathrm{Cl}$ & $\mathrm{p}$-value \\
\hline Altitude & $\leq 1200 \mathrm{~m}^{\mathrm{a}}$ & 17.1 & $16.6,17.6$ & $<0.001$ \\
& $>1200 \mathrm{~m}, \leq 1300 \mathrm{~m}$ & 12.0 & $11.6,12.5$ & \\
& $>1300 \mathrm{~m}, \leq 1400 \mathrm{~m}$ & 13.6 & $13.2,14.0$ & \\
& $>1400 \mathrm{~m}, \leq 1500 \mathrm{~m}$ & 5.9 & $5.5,6.2$ & \\
& $>1500 \mathrm{~m}$ & 12.0 & $10.9,13.2$ & \\
Year & 2009 & 10.4 & $10.1,10.7$ & $<0.001$ \\
& 2010 & 18.3 & $17.9,18.7$ & \\
& 2011 & 6.0 & $5.7,6.4$ & \\
Regional state & Benshangul-Gumuz & 32.7 & $31.8,33.6$ & $<0.001$ \\
& Amhara & 3.3 & $3.1,3.5$ & \\
& Oromia & 14.5 & $14.1,14.8$ & \\
River system & Abay Didessa & 2.9 & $2.5,3.5$ & $<0.001$ \\
& Abay & 12.3 & $12.0,12.7$ & \\
& Baro Akobo & 14.5 & $14.1,14.8$ & \\
\hline
\end{tabular}

morsitans group to infections by $T$. congolense [39]. In contrast, the lowest prevalence rates were observed in PAs of Dalesadi and Dalewabara districts where four species of Glossina were trapped. In $14.6 \%$ of the PAs $(n=12)$, no trypanosomes were detected (Fig. 1). From our data, except for the higher susceptibility of the morsitans group to trypanosome infections, no clear explanation could be given for those variations (e.g. land cover, consistent link to a particular vector species). However, looking at the literature some common factors are associated with prevalence variability: annual and seasonal differences in sampling time, cattle abundance at watering places, micro-environmental ecological conditions [40-42], variations in tsetse and other hematophagous fly (mainly Stomoxis spp. and tabanids) densities and their respective vectorial capacity and seasonality [43-45] and the trypanotolerance/susceptibility of local cattle breeds [25, 40, 46].

The susceptibility of male cattle to trypanosome infections was higher than that of females. This can be explained by (i) their higher attractiveness for flies, (ii) a higher stress linked to their use as draft animals and (iii) the malnourishment of young males used prematurely for traction work with an insufficient food supply. Similar situations were reported in Ethiopia and Zambia [36, 47, 48].

\section{Glossina}

A total of 14,698 tsetse flies were trapped. Four different species were identified i.e. G. tachinoides (52 \%), G. pallidipes (26\%), G. morsitans submorsitans (15\%) and G. fuscipes fuscipes (7\%). Significant differences in AT were observed between districts globally and for each of the Glossina species separately.

Qualitatively, Dale Sadi and Dale Wabera districts were colonized by four Glossina species whilst one, two or three 
species prevailed in the remaining 8 districts (Table 5). In Asosa district, only G. m. submorsitans was observed, which is probably due to the fact that Asosa is characterized by an unspoiled savannah environment, as this species is particularly sensitive to encroachment. Additionally this area is not drained by large rivers, which explains the absence of riverine flies. In the other districts, ecological features are more diverse, providing niches for different coexisting species. A number of reports have shown that the overlapping of two to three tsetse species is common $[49,50]$. G. pallidipes, G. m. submorsitans, G. tachinoides and G. f. fuscipes were heterogeneously distributed in the western and north western zones of Ethiopia which is in agreement with previous studies [16, 17].

Differences in the flies' sex ratios were noticed for G. $m$. submorsitans ( 1 male to 1.37 females), G. pallidipes (1 male to 1.32 females) and G. f. fuscipes (1 male to 1.22 females). Females are over-represented by 22 to $37 \%$ for each species. This is in agreement with the reports of Leak in 1999 [38] who reported that females would represent $70 \%$ to $80 \%$ in unbiased sampling. A number of causal factors for the sex ratio distortion in favour of females include (i) selective attractiveness of the trap [38, 51], (ii) a longer life expectancy of females compared to males [52], (iii) male reproducers transmitting X-bearing or a nonfunctional Y-bearing sperm [53] and (iv) a higher mortality rate of the males because of their higher susceptibility to insecticides [54].

Quantitatively, the AT varied from PA to PA. Indeed, different ecological contexts are obviously translated by different fly densities and species compositions [11]. Low altitude was significantly and positively associated with AT. Indeed, altitude directly influences ecological parameters such as vegetation cover and structure inducing specific microclimatic zones at different elevations [22, 38]. Additionally, lower temperature at night limits the pupal development and scarcer vegetation renders the environment more stressful for tsetse flies. In Nigeria an odds ratio of 0.91 per $50 \mathrm{~m}$ altitude increase was observed with an upper limit of $1800 \mathrm{~m}$ a.s.l. above which no tsetse flies were observed $[55,56]$. Our data confirms this observation except for the sole PA of Abuna Gali were high catches were observed despite the altitude being above $1500 \mathrm{~m}$.

Table 5 The multivariable model presenting the risk factors associated with tsetse fly abundance in Ethiopia

\begin{tabular}{lllll}
\hline Risk factor & Category & IRR & $95 \% \mathrm{Cl}$ & p-value \\
\hline Altitude & $\leq 1200 \mathrm{~m}^{\mathrm{a}}$ & 1 & - & - \\
& $>1200 \mathrm{~m}, \leq 1300 \mathrm{~m}$ & 0.71 & $(0.67,0.74)$ & $<0.001$ \\
& $>1300 \mathrm{~m}, \leq 1400 \mathrm{~m}$ & 0.79 & $(0.76,0.83)$ & $<0.001$ \\
& $>1400 \mathrm{~m}, \leq 1500 \mathrm{~m}$ & 0.34 & $(0.32,0.37)$ & $<0.001$ \\
& $>1500 \mathrm{~m}$ & 0.70 & $(0.63,0.78)$ & $<0.001$ \\
\hline
\end{tabular}

With IRR Incidence Rate Ratio, $\mathrm{Cl}$ Confidence Interval, ${ }^{a}$ reference
The data of this sole PA is pulling the entire category upwards. The most likely explanation for this, is a vegetation particularly dense for this altitude and the proximity of a permanent river that is connected by small seasonal tributaries to the river system of the Didessa wildlife reserve situated $80 \mathrm{~km}$ East from Abuna Gali.

Altitude, presence or absence of rivers, trees and wildlife are certainly determining factors for fly abundance but one of the main factors that remains is human encroachment. Indeed, tsetse and human population densities are negatively correlated and tsetse fail to survive in areas inhabited by more than 40 people per $\mathrm{km}^{2}$ [57]. This is particularly true for G. m. submorsitans, which is very sensitive to habitat degradation. The varying intensity of tsetse control in each region can somewhat contribute to the observed variations. Unfortunately, no data was available to perform the analysis to substantiate this possibility.

Despite many years spent on tsetse and trypanosomosis control, the problem persists due to mismanagement of available disease control means particularly in terms of geographical distribution and choice of control measures $[2,11]$.

\section{Relationship between tsetse abundance and trypanosome prevalence}

No relationship between AT and trypanosomosis prevalence was found (Odds Ratio $=1,95 \%$ CI: [0.99; 1], $p=$ 0.348 ) in the 30 PAs where the comparison was made. This is mainly due to the fact that at low densities the trypanosomosis prevalence varied a lot, from 0 to very high levels. This might be partially explained by an increased vectorial capacity of flies under adverse conditions [58]. Indeed, starvation and high ambient temperatures increase the susceptibility of tsetse flies to trypanosome infections [59, 60], hence increasing the rate of transmission with subsequently increased trypanosomosis prevalence in animals. Another factor that should not be immediately discarded is the possibility of mechanical transmission of trypanosomes by hematophagous flies as previously described for T. vivax and T. congolense [61-63] and more specifically in Ethiopia [64-67]. However, in our study, the tsetse abundance was not adjusted for the tsetse infection rate rendering the estimation of the real tsetse challenge impossible and consequently, the link between the tsetse challenge and AAT prevalence [68]. Further experimental data is thus needed to know if a reduction in tsetse challenge would lead to a significant reduction in trypanosomosis prevalence [40]. Furthermore, the link between AT and trypanosomosis prevalence is weakened by the fact that cattle bred in PAs located far from rivers and/or suitable tsetse habitats, travel longer distances to reach watering points and grasslands in the dry season: cattle is being 
brought to the vectors. During the rainy season, water and shade are widespread; cattle are walking shorter distances but flies are more dispersed in this tsetse-favouring environment. The vector host interface is thus facilitated.

\section{Conclusions}

The present study provides a recent update on AT and on trypanosomosis prevalence in the southwest of Ethiopia together with the associated risk factors. Despite increasing human encroachment and vector/disease control operations tsetse are still abundant in the studied region and trypanosomosis remains an impediment to livestock health and production. The high trypanosomosis prevalence with low or nil ATs should be further investigated so that coordinated control strategies can be established.

\section{Competing interests}

The authors declare that they have no competing interests.

\section{Authors' contributions}

$R D, L D$ and $V D$ conceived and executed the study. RD, VD, LD and AH interpreted the results and drafted the manuscript. RD, ST, AO, DD, DA, TM, YA, MY, MB conducted the parasitological and entomological surveys and compiled the results. RD, YA, EA and LD performed the GIS and statistical analysis. VD, LD, TH and AH improved and corrected the manuscript. All authors read, commented and approved the final manuscript.

\section{Acknowledgement}

We would like to thank the Agricultural Bureau of the four Regional States and the Bedele National Trypanosomosis and Tsetse Control Centre for their support during the field work. The VLIR-UOS is also acknowledged for financial support for the whole trypanosomosis project in the framework of the Institutional University Cooperation - Jimma University (IUC-JU) project ZIUS2014AP014.

\section{Author details \\ 'Department of Clinical studies, College of Veterinary Medicine and Agriculture, Addis Ababa University, P.O.Box 34, Bishoftu, Oromia, Ethiopia. ${ }^{2}$ Department of Comparative Physiology and Biometrics, Faculty of Veterinary Sciences, Universiteit Gent, Salisburylaan 133, B-9820 Merelbeke, Belgium. ${ }^{3}$ National Tsetse and Trypanosome Investigation and Control Centre, P.O.Box 13, Illu-Aba-Bora, Bedelle, Ethiopia. ${ }^{4}$ National Animal Health Diagnostic and Investigation Centre, P.O. Box 04, Sebeta, Oromia, Ethiopia. ${ }^{5}$ International Maize \& Wheat Improvement Centre (CIMMYT), Socio-economics Program, Global Cereal Rust Monitoring system, P.O. Box 5689, Addis Ababa, Ethiopia. ${ }^{6}$ Department of Microbiology and Veterinary Public Health, School of Veterinary Medicine, Jimma University, P.O. Box 307, Jimma, Ethiopia. ${ }^{7}$ Institute for Parasitology and Tropical Veterinary Medicine, Freie Universitaet Berlin, Robert-von-Ostertagstr. 7-13, 14163 Berlin, Germany. ${ }^{8}$ Department of Biomedical Sciences, Institute of Tropical Medicine, Nationalestraat 155, Antwerp, Belgium.}

\section{Received: 30 March 2015 Accepted: 10 August 2015}

\section{Published online: 19 August 2015}

\section{References}

1. Baumgärtner J, Gilioli G, Tikubet G, Gutierrez AP. Eco-social analysis of an East African agro-pastoral system: Management of tsetse and bovine trypanosomiasis. Ecol Econ. 2008;65:125-35.

2. Jemal A, Hugh-Jones ME. Association of tsetse control with health and productivity of cattle in the Didessa Valley, western Ethiopia. Prev Vet Med. 1995:22(94):29-40.

3. Kristjanson PM, Swallow BM, Rowlands GJ, Kruska RL, de Leeuw PN. Measuring the costs of African animal trypanosomosis, the potential benefits of control and returns to research. Agric Syst. 1999;59(1):79-98.
4. Mohamed Ahmed MM, Dairri MF. Trypanosome infection rate of Glossina pallidipes during wet and dry seasons in Somalia. Trop Anim Health Prod. 1987;19:11-20.

5. Murray M, Gray ARRR, Murray M, Gray AR, Murray M, Gray ARRR. The current situation on animal trypanosomiasis in Africa. Prev Vet Med. 1984;2(1-4):23-30.

6. Dejene A. Environment, Famine and Politics in Ethiopia: A View from the Village. Boulder: Lynne Rienner; 1990.

7. Comenetz J, Caviedes C. Climate variability, political crises, and historical population displacements in Ethiopia. Environ Hazards. 2002;4:113-27.

8. Reid RS, Kruska RL, Muthui N, Taye A, Wotton S, Wilson CJ, et al. Land-use and land-cover dynamics in response to changes in climatic, biological and socio-political forces: The case of southwestern Ethiopia. Landsc Ecol. 2000;15:339-55.

9. Wood A. Natural Resource Conflicts in South-West Ethiopia: State Communities, and the Role of the National Conservation Strategy in the Search for Sustainable Development. Nord J African Stud. 1993;2:83-102.

10. Lee CW, Maurice JM. The African Trypanosomiases: Methods and Concepts of Control and Eradication in Relation to Development. Washington: World bank; 1983.

11. Slingenbergh J. Tsetse control and agricultural development in Ethiopia. World Anim Rev. 1992;70-71:30-6.

12. Afewerk Y, Clausen PH, Abebe G, Tilahun G, Mehlitz D. Multiple-drug resistant Trypanosoma congolense populations in village cattle of Metekel district, north-west Ethiopia. Acta Trop. 2000;76:231-8.

13. Tewelde N, Abebe G, Eisler MC, McDermott JJ, Greiner M, Afework Y, et al. Application of field methods to assess isometamidium resistance of trypanosomes in cattle in western Ethiopia. Acta Trop. 2004;90(2):163-70.

14. Moti GY, Fikru R, Van Den Abbeele J, Büscher P, Van den Bossche P, Duchateau $L$, et al. Ghibe river basin in Ethiopia: present situation of trypanocidal drug resistance in Trypanosoma congolense using tests in mice and PCR-RFLP. Vet Parasitol. 2012;189(2-4):197-203. doi:10.1016/ j.vetpar.2012.04.022.

15. Malele II, Nyingilili H, Msangi A. Factors defining the distribution limit of tsetse infestation and the implication for livestock sector in Tanzania. African J Agric Res. 2011;6(10):2341-7.

16. Vreysen MJB, Mebrate A, Menjeta M, Bancha B, Woldeyes G, Musie K, et al. The distribution and relative abundance of tsetse flies in the southern rift valley of Ethiopia: preliminary survey results. Proc Int Sci Counc Trypanos Res Control (ISCTRC). 1999;120:202-13.

17. Tikubet $\mathrm{G}$, Gemetchu T. Altitudinal distribution of tsetse in the Finchaa river valley (western part of Ethiopia). Int J Trop Insect Sci. 1984;5(05):389-95.

18. Brightwell B, Dransfield B, Maudlin I, Stevenson P, Shaw APM. Reality vs. rhetoric - a survey and evaluation of tsetse control in East Africa. Agric Human Values. 2001;18:219-33.

19. Rogers DJ, Randolph SE. A review of density-dependent processes in tsetse populations. Int J Trop Insect Sci. 1984;5(05):397-402.

20. Langride WP. A Tsetse and Trypanosomosis Survey of Ethiopia. Ministry of Overseas Development; 1976

21. Awulachew SB, Yilma AD, Loulseged M, Loiskandl W, Ayana M, Alamirew T. Ethiopian water resources potential and development in Africa. Rep Minist Water Energy 2011:1 - 82

22. Institute of biodiversity and conservation (ICB). Ecosystems of Ethiopia. 2007: http://www.ibc.gov.et/ibc/ecosm/.

23. Abebe YD. A Glimpse at Biodiversity Hotspots of Ethiopia. Addis Ababa: Addis Ababa Ethiopian Wildlife and Natural History Society; 2010. p. 1-94.

24. Reusing M. Change detection of natural high forests in Ethiopia using remote sensing and GIS techniques. Int Arch Photogramm Remote Sens. 2000;33(B7):1253-8.

25. Lemecha H, Mulatu W, Hussein I, Rege E, Tekle T, Abdicho S, et al. Response of four indigenous cattle breeds to natural tsetse and trypanosomosis challenge in the Ghibe valley of Ethiopia. Vet Parasitol. 2006;141(1-2):165-76.

26. Woo PTK. The haematocrit centrifuge technique for the diagnosis of African trypanosomiasis. Acta Trop 1970;27:384-87.

27. Luckins AG. Methods for diagnosis of trypanosomosis in livestock. World Anim Rev. 1992;70(71):15-20.

28. Gouteux JP, Lancien J, Noireau F, Sinda D. Tsetse control by trapping and its impact on the transmission of sleeping sickness in the high density area of Glossina fuscipes quanzenis (Lefini River, Democratic Republic of Congo). Trop Med Parasitol. 1986;37(2):101-4.

29. Vale GA. Proceedings: Attractants for controlling and surveying tsetse populations. Trans R Soc Trop Med Hyg. 1974;68(1):11. 
30. Dean GJ, Clements SA, Paget J. Observation on some possible attractants of tsetse flies (Glossina morsitans Westw. and G. pallidipes Aust.). Bull Entomol Res. 1969;59(3):423-34.

31. VanLeeuwen JA, Haddad JP, Dohoo IR, Keefe GP, Tiwari A, Scott HM. Risk factors associated with Neospora caninum seropositivity in randomly sampled Canadian dairy cows and herds. Prev Vet Med. 2010;93:129-38.

32. Hosmer DW, Lemeshow S, Sturdivant RX. Applied Logistic Regression. Hoboken: Wiley series in statistics and regression; 2013.

33. Dohoo I, Wayne M, Stryhn H. Veterinary Epidemiologic Research. 2nd ed. Charlottetown: VER Inc; 2003.

34. McCullagh P, Nelder JA. Generalized Linear Models: Monographs on Statistics and Applied Probability 37. 2nd ed. New York: Springer-Science + Business Media, B.V; 1989

35. Mekuria S, Gadissa F. Survey on bovine trypanosomosis and its vector in Metekel and Awi zones of Northwest Ethiopia. Acta Trop. 2011;117(2):146-51.

36. Tasew S, Duguma R. Cattle anaemia and trypanosomiasis in western Oromia State, Ethiopia. Rev Med Vet (Toulouse). 2012;163(12):581-8.

37. Abebe G. Trypanosomiasis: a threat to cattle production in Ethiopia. Rev Med Vet (Toulouse). 1996;147:897-902.

38. Leak SGA. Tsetse Biology and Ecology: Their Role in the Epidemiology and Control of Trypanosomosis. Wallingford: CABI Publishing; 1999.

39. Reifenberg JM, Cuisance D, Frezil JL, Cuny G, Duvallet G. Comparison of the susceptibility of different Glossina species to simple and mixed infections with Trypanosoma (Nannomonas) congolense savannah and riverine forest types. Med Vet Entomol. 1997;11(3):246-52.

40. Leak SGA, Collardelle C, Coulibaly L, Dumont P, Feron A, Hecker P, et al. Relationships between tsetse challenge and trypanosome prevalence in trypanotolerant and susceptible cattle. Int J Trop Insect Sci. 1990;11:293-9.

41. Specht EJK. Prevalence of bovine trypanosomosis in Central Mozambique from 2002 to 2005. Onderstepoort J Vet Res. 2008;75(1):73-81.

42. Hoppenheit A, Steuber S, Bauer B, Ouma EM, Diall O, Zessin KH, et al. Host preference of tsetse: an important tool to appraise the Nagana risk of cattle in the cotton zone of Mali. Wien Klin Wochenschr. 2010;122 Suppl 3:81-6.

43. Ahmed AB, Okiwelu SN, Samdi SM. Species diversity, abundance and seasonal occurrence of some biting flies in Southern Kaduna, Nigeria. African J Biomed Res. 2005;8:113-8.

44. Tchouomene-Labou J, Nana-Djeunga H, Simo G, Njitchouang GR, Cuny G, Asonganyi T, et al. Spatial and temporal variations relevant to tsetse control in the Bipindi focus of southern Cameroon. Parasit Vectors. 2013;6:193.

45. Hoppenheit A, Bauer B, Steuber S, Terhalle W, Diall O, Zessin KH, et al. Multiple host feeding in Glossina palpalis gambiensis and Glossina tachinoides in southeast Mali. Med Vet Entomol. 2013;27(2):222-5.

46. Stein J, Ayalew W, Rege E, Mulatu W, Lemecha H, Tadesse Y, et al. Trypanosomosis and phenotypic features of four indigenous cattle breeds in an Ethiopian field study. Vet Parasitol. 2011;178:40-7.

47. Simukoko H, Marcotty T, Phiri I, Vercruysse J, Van den Bossche P. Heterogeneity in the trypanosomosis incidence in Zebu cattle of different ages and sex on the plateau of eastern Zambia. Acta Trop. 2007;103:98-101.

48. Conner RJ. Improving draught animal management with strategic chemotherapy 747 control of trypanosomosis. In: improving animal traction technology. Workshop of the animal traction network for Eastern and Southern Africa, Lusaka, Zambia. 1994.

49. Gouteux JP, Jarry M. Tsetse flies, biodiversity and the control of sleeping sickness. Structure of a Glossina guild in southwest Côte d'lvoire. Acta Oecologica. 1998;19:453-71.

50. Malele II, Kinung'hi SM, Nyingilili HS, Matemba LE, Sahani JK, Mlengeya TDK, et al. Glossina dynamics in and around the sleeping sickness endemic Serengeti ecosystem of northwestern Tanzania. J Vector Ecol. 2007;32:263-8.

51. Rowlands GJ, Mulatu W, Authie EML, Dieteren GDM, Leak SGA, Nagda SM, et al. Epidemiology of bovine trypanosomiasis in the Ghibe Valley, Southwest Ethiopia. Factors associated with variations in trypanosome prevalence, incidence of new infections and prevalence of recurrent infections. Acta Tropica. 1993;53(2):135-50

52. Buxton PA. The Natural History of Tsetse Flies. An Account of the Biology of the Genus Glossina (Diptera). London: London School of Hygiene \& Tropical Medicine (Memoir No. 10); 1955.

53. Rawlings $P$, Maudlin I. Sex ratio distortion in Glossina morsitans submorsitans Newstead (Diptera: Glossinidae). Bull Entomol Res. 2009;74(02):311.

54. Burnett GF. The susceptibility of tsetse flies to topical applications of insecticide. Young adults of Glossina morsitans Westwood and organophosphorus compounds, pyrethrins and Sevin. Bull Entomol Res. 1961;52(04):763. http://dx.doi.org/10.1017/S0007485300055759.

55. Majekodunmi AO, Fajinmi A, Dongkum C, Picozzi K, MacLeod ET, Thrusfield $M V$, et al. Social factors affecting seasonal variation in bovine trypanosomiasis on the Jos Plateau, Nigeria. Parasit Vectors. 2013;6:293.

56. Jordan AM. Trypanosomosis Control and African Rural Development. London: Longman Group Ltd; 1986.

57. Ford J. African' wildlife' and the tsetse fly-borne diseases. Bull Epizoot Dis Africa. 1962;10:9-12

58. Akoda K, Van den Abbeele J, Marcotty T, De Deken R, Sidibe I, Van den Bossche P. Nutritional stress of adult female tsetse flies (Diptera: Glossinidae) affects the susceptibility of their offspring to trypanosomal infections. Acta Tropica. 2009;111(3):263-7.

59. Kubi C, Van Den Abbeele J, De Deken R, Marcotty T, Dorny P, Van den Bossche $P$. The effect of starvation on the susceptibility of teneral and non-teneral tsetse flies to trypanosome infection. Med Vet Entomol. 2006;20(4):388-92.

60. Bouyer J, Koné $N$, Bengaly Z. Dynamics of tsetse natural infection rates in the Mouhoun river, Burkina Faso, in relation with environmental factors. Front Cell Infect Microbiol. 2013;3:47.

61. Desquesnes M, Dia ML. Trypanosoma vivax: mechanical transmission in cattle by one of the most common African tabanids, Atylotus agrestis. Experimental Parasitology. 2003;103(1-2):35-43.

62. Desquesnes M, Dia ML. Mechanical transmission of Trypanosoma vivax in cattle by the African tabanid Atylotus fuscipes. Vet Parasitol. 2004;119(1):9-19.

63. Desquesnes M, Dia ML. Mechanical transmission of Trypanosoma congolense in cattle by the African tabanid Atylotus agrestis. Exp Parasitol. 2003;103(1-2):35-43.

64. Roeder PL, Scott JM, Pegram RG. Acute Trypanosoma vivax infection of ethiopian cattle in the apparent absence of tsetse. Trop Anim Health Prod. 1984;16(3):141-7.

65. Cherenet T, Sani RA, Speybroeck N, Panandam JM, Nadzr S, Van den Bossche P. A comparative longitudinal study of bovine trypanosomiasis in tsetse-free and tsetse-infested zones of the Amhara Region, northwest Ethiopia. Vet Parasitol. 2006;140(3-4):251-8.

66. Sinshaw A, Abebe G, Desquesnes M, Yoni W. Biting flies and Trypanosoma vivax infection in three highland districts bordering lake Tana, Ethiopia. Vet Parasitol. 2006;142:35-46.

67. Fikru R, Goddeeris BM, Delespaux V, Moti GY, Tadesse A, Bekana M, et al. Widespread occurrence of Trypanosoma vivax in bovines of tsetse- as well as non-tsetse-infested regions of Ethiopia: A reason for concern? Vet Parasitol. 2012;190(1873-2550 (Electronic)):355-61.

68. Dicko AH, Percoma L, Sow A, Adam Y, Mahama C, Sidibé I, et al. A Spatiotemporal Model of African Animal Trypanosomosis Risk. PLoS Negl Trop Dis. 2015;9(7):e0003921.

\section{Submit your next manuscript to BioMed Central and take full advantage of:}

- Convenient online submission

- Thorough peer review

- No space constraints or color figure charges

- Immediate publication on acceptance

- Inclusion in PubMed, CAS, Scopus and Google Scholar

- Research which is freely available for redistribution 